\title{
How do monetary policy tools work? An investigation on monetary transmission mechanism in Iran
}

\author{
Naser Ali Yadollahzadeh Tabari* and Mohammad Nasrollahi
}

Department of Economics, Babol Branch, Islamic Azad University, Babol, Iran

\section{H R O N I C L E A B T R A C T}

Article history:

Received October 29, 2012

Received in revised format

1 March 2013

Accepted 4 March 2013

Available online

March 62013

Keywords:

Monetary policy

Price level

Output

Nominal effective exchange rate

\begin{abstract}
Monetary transmission mechanism includes some channels in which monetary policy influences on macroeconomic variables such as the output and inflation. In this study, the effect of monetary policy tools including interest rate, exchange rate and money supply on the variables of monetary policy targets including inflation and output is examined through VECM methodology over the period 1989:2-2007:2. Our findings show that in long-term, monetary supply is the most important variable influencing the price followed by the variables of output and exchange rate, respectively. Exogenous-being of interest rate indicates that this channel is underdeveloped and there is no monetary policy rule like Taylor rule in Iran's economy.
\end{abstract}

(C) 2013 Growing Science Ltd. All rights reserved.

\section{Introduction}

The most important condition to execute an effective monetary policy is a meaningful and steady relationship between policy tools of central bank and the inflation through monetary transmission technique (Al-Mashat \& Billmeier, 2008; Dabla-Norris et al., 2007). For this reason, a good understanding the effects of policy tools used by central bank on inflation, such as inflation targeting framework, plays an essential role on the success of monetary policy regime. Since uncertainties associated with monetary policy transmission mechanism influences total demand and inflation, it is necessary to study relatively complex relationships between monetary policy tools and key variables of economy including inflation and output to ensure a good selection of an appropriate policy tools during current time and achievement of the determined results in the future (Boughrara \& Erriadh, 2003). The purpose of this study is to examine the potential channels of monetary transmission mechanism towards total demand and inflation to see whether there is a possibility of performing a monetary policy framework including inflation targeting in Iran.

\footnotetext{
Corresponding author. Tel: +989113130334

E-mail addresses: nasertabari@yahoo.com (N. Ali Yadollahzadeh Tabari)

(C) 2013 Growing Science Ltd. All rights reserved.

doi: 10.5267/j.msl.2013.03.007
} 
The proposed study of this paper uses VECM methodology to evaluate the impact of monetary policy tools on the levels of output and prices. On the other hand, regarding to monetary transmission mechanism, we aim to elaborate appropriate policy tools used by Iran's central bank to control price fluctuations and to achieve a special inflation target. During post-revolution years, the monetary and banking policies included the enactment of limiting banking rules, real negative interest rates of bank loans and deposits, wide interventions of government in the banking system and financing the budget deficit through banking resources. These conditions prevented to execute the efficient monetary policies to control inflation pressures and to develop financial mediation. In these years, an effective implementation of indirect techniques of monetary policies such as the appropriate change in the banks' interest rates and open market operations or exchange sterilization was not made. During these years, required reserve ratio was at maximum level. In fact, until before the beginning of third development plan, there was no virtual monetary policy in the country and desultory approvals in this respect were associated with notes of annual budgets. Prior to year 2000, monetary policy management in Iran was influenced by fiscal dominance and parallelism of world oil price with the government budget. Besides, the problems of repayment of the country's foreign debts, affected all perspectives of the economy over the period 1993-1994 and 1997-1998 and, subsequently, the government dominance on financial and monetary organizations intensified (Bonato, 2007). Although the years of the third plan was formally defined as monetary targeting but this framework was executed, very incompletely.

\section{Material and Methods}

These days, central banks select their own special strategies to execute monetary policy by targeting important goals (Mishkin \& Schmidt-Hebbel, 2007). One important issue is to know whether the selected operational frameworks are compatible with the nature of monetary transmission policies or not. Based on various experiences of different countries for establishing an efficient monetary system to control inflation, it can be stated that monetary policy tools should include different criteria. First, it should be controllable by central bank, there must be a strong correlation between the policy and inflation rate. The index must be easily measurable with no ambiguity and finally, it needs to be relatively easy to predictable. The selection of tools is normally based on the empirical analysis of monetary transmission policy mechanism.

Monetary transmission mechanism includes monetary policy effects on total demand and level of prices through influencing investment and consumption decisions of agencies, households as well as financial agencies. Today, money neutrality hypothesis of Neoclassical has widely been accepted in long-term, but it is assumed that in short-term and middle-term, monetary policy through change in the interest rates and money supply. These are because of the existence of rigidity in nominal price as well as wealth, income and cash effects and through its effect on the inflation expectations, monetary policy influences on economic activities (Dabla-Norris \& Floerkemeier, 2006). There are normally six monetary transmission distinguished mechanisms in a relatively small developed open economy including 1) banking loan channel/ credit channel; 2) exchange rate channel; 3) interest rate channel; 4) balance sheet channel; 5) property channel, and 6) expectations channel (Mishkin \& SchmidtHebbel, 2007). Systematically, there are various functions of monetary mechanism channels in different countries. These functions depend on financial development, banking system health, development of capital markets and the structure of economy (Cecchetti \& Ehrmann, 1999; Gottschalk \& Moore, 2001). There are various characteristics on macroeconomic variables and the structural circumstances of the economy such as monetization, cash payments system, size of informal sector of economy, openness degree of economy to detect the relationship between financial conditions and investment decisions of the households and various agencies by themselves. Empirical evidence have indicated that although interest rate channel plays important role on transmission in the industrialized countries with the developed financial markets, but in transitional countries, exchange rate channel is considered as the primary channel for monetary transmission policy (Coricelli et al., 
2005). Interest rate, credit, balance sheet and asset price channels have emerged strongly inefficient in under developing financial intermediary system. Of course, the efficiency of exchange rate channel could be relatively high since it not only influences on the aggregate demand but also it impacts on aggregate supply through cost-based structure (Juks, 2004). The primary outcome of an inefficient monetary transmission mechanism appears in weak relationship between interest rate as a monetary policy tool and other rates, which decrease the impact on investment, consumption and aggregate demand because of weakness in direct channel of interest rate and the credit channel. Under such circumstances, intervention in exchange market plays important rule for monetary policy targets.

In this paper, we examine the relationship between potential policy variables of central bank, in terms of short-term interest rate, exchange rate and money supply, and two target variables of general level of prices and national output in Iran. We aim to evaluate the relative importance of policy tools of central bank to determine the changes of these two target variables using a VAR model to make it clear whether each of these components can act as policy variable of central bank or not. The proposed model of this paper uses VAR model by looking at the value and significance of ECM feedback coefficients in short-term error correction model. For instance, the existence of CPI equation in VAR model is useful for measuring the strength of relationship between policy tools and inflation changes. If there is a strong relationship between monetary policy tools and inflation, then delayed changes in monetary policy tools are important and are statistically significant to illustrate CPI. Each central bank selects a special strategy to perform monetary policy by targeting important variables (Mishkin \& Schmidt-Hebbel, 2007). The important question is whether the selected operational frameworks are compatible with the nature of monetary transmission policy mechanism or not. Based on the past experiences it can be expressed that monetary policy tools need to be under central bank's control, the index has to be strongly in association with inflation, it needs to be easily measurable and finally the index needs to be easily forecasted. The selection of tools is usually based on the empirical surveying the monetary transmission policy mechanism.

Monetary transmission mechanism represents some techniques to measure the effects of monetary policy on total demand and price levels through different figures influencing investment and consumption decisions of agencies, households and financial agents. These days, money neutrality hypothesis of Neoclassical has widely been accepted in long-term, but it is assumed that in short-term and middle-term, monetary policy through change in the interest rates and money supply. These two items are in association with the existence of rigidity in nominal price and because of wealth, income and cash effects. Finally, the effects of the inflation expectations, monetary policy influence on economic activities (Dabla-Norris \& Floerkemeier, 2006). Generally, six monetary transmission mechanisms exist in a small developed open economy including banking loan channel/ credit channel, exchange rate channel, interest rate channel, balance sheet channel, property channel, and expectations channel (Mishkin \& Schmidt-Hebbel, 2007).

Monetary mechanism channels are different in various countries depending on financial development, banking system health, development of capital markets and the structure of economy (Cecchetti \& Ehrmann, 1999). The macroeconomic variables and the structural circumstances of the economy determine the relationship between financial conditions and investment decisions of the households and agencies. Some studies have shown that although interest rate channel is the most important channel of transmission in the industrialized countries to the developed financial markets, but in transitional countries, exchange rate channel is generally the main channel for monetary transmission policy (Coricelli et al., 2005). Interest rate, credit, balance sheet and asset price channels are emerged strongly inefficient in a non-developed financial intermediary system. The relative efficiency of exchange rate channel is normally at a high level since it not only influences the aggregate demand but also it influences on aggregate supply through cost-based structure (Juks, 2004). The immediate consequences of an inefficient monetary transmission mechanism is the weak relationship between interest rate as a monetary policy tool and other rates which reduce the impact of the investment, 
consumption and aggregate demand because of the weakness of direct channel of interest rate and the credit channel. Under these circumstances, intervention in exchange market is proposed as an important tool for monetary policy targets.

\section{The proposed method}

\subsection{Variables and their time series characteristics}

One of the most important challenges for evaluating the monetary transmission mechanism in Iran is to find a method to represent monetary policy stance. In developed countries, short-term interest rates are the primary source of monetary policy for central banks. In this research, we use short-term interest rate, three-month deposits $(\mathrm{R})$ as potential figures for monetary policy in Iran. Nominal exchange rate is the second variable associated with monetary policy. The proposed model of this paper adopts Dabla-Norris and Floerkemeier (2006) method and emphasizes on nominal effective exchange rate $(E)$ to test the effects of exchange rate on the output and prices. We use E instead of real effective exchange rate, REEER, which helps us distinguish exchange rate channel from other channels more easily. We are able to determine the effects of change in nominal exchange rate on real economic activities separating from the change in the prices. In fact, since real exchange rate is already adjusted compared with the changes in prices, the separation of the impacts of change in the price and the impacts of change in exchange rate are challenging task. Third variable associated with monetary policy is the narrow definition of money, i.e. M1.

The output was considered as real gross domestic product (GDP) and consumer price index (CPI) and it is regarded as the measure for general level of prices. Foreign price levels (WP) is also added to the model in order to consider the effects of foreign inflation on internal variables of the economy. All the variables are logarithmic except interest rate, which is expressed in levels. The seasonal dummy variables are used to consider the seasonal fluctuations and dummy variables of D71 and D74 are used to consider the impacts of exchange rate release in 1992 and the intensive inflation, respectively. Data related to general levels of prices, supply of money, real GDP and interest rate of three-month deposits are obtained from the statistics of central bank of Islamic Republic of Iran seasonally over the period 1989:2-2007:2. Nominal effective exchange rate and the levels of foreign prices are drawn from database of International Financial Statistics (IFS) during the studied period. In order to study the stationary of the variables, the Augmented Dickey-Fuller (ADF) test was conducted. The results indicate that all series are I(1). Of course, first differences of these variables are stationary.

\subsection{Estimation of long-term and short-term relationships}

In this section, we will attempt to analyze the determinant factors of the prices and output in shortterm and long term. The variables ' vector is as follows:

$\mathrm{Y}_{\mathrm{t}}=[\mathrm{DP}, \mathrm{Y}, \mathrm{M}, \mathrm{R}, \mathrm{E}, \mathrm{WP}]$

In this study, Johnson's maximum likelihood method is implemented for cointegration analyses. The cointegration analysis are based on Johnson's procedure and determines optimal lag length (P) in vector autoregressive model and we consider it as $\mathrm{P}=2$ based on Hannan-Quinn Criterion. To determine the number of long-term equilibrium relationships (cointegrated space dimensions), the integrated tests based on Trace and Maximum Eigen Value are implemented. In this relationship, according to the results of Trace test in better compatibility with the economic theories, we consider the number of long-term relations equal to $r=2$.

Based on economic theories and after exerting just identification restrictions, first and second vector were normalized according to $D P$ and $E$, respectively. Next, by applying exogenous tests and 
examining the sign, value and statistical significance of ECM feedback coefficients, the accuracy of selection of long-term relationships of general level of prices and nominal effective exchange rate were tested. The obtained results are presented in Table 1.

Table 1

Summary of VECM estimation

\begin{tabular}{lcccccc}
\hline & World Prices (WP) & Interest Rate (R) & Exchange Rate (E) & Output (Y) & Money Supply (M) & Price Level (DP) \\
\hline Eq. (1) & 0.00 & -0.07 & 0.19 & 0.21 & -0.7 & 1.00 \\
& ---- & $(-3.18)$ & $(5.43)$ & $(3.21)$ & $(-18.0)$ & ---- \\
\hline Eq. (2) & 1.92 & 0.00 & 1.00 & -1.44 & 0.00 & 0.47 \\
& $(9.07)$ & --- & --- & $(-33.05)$ & --- & $(3.77)$ \\
\hline
\end{tabular}

Note: The VECM was estimated using two lags in each equation. Absolute t-values are given in parentheses. SEE stands for the

standard error of the equation.

The coefficients of first vector considered as consumer price index vector, have the signs expected for economic theories. As it is observed, in this long-term relationship, the coefficient of money supply (M) is equal to 0.7 and it is statistically significant, which represents the positive and powerful effect of money supply on general level of prices in long-term. Nevertheless, the quantity theory of money based on a one-by-one relationship between growth rate of money supply and inflation in Iran's economy is not completely confirmed. The difference can be probably resulted from price controls and extensive import, which prevents the complete adjustment in the market of some goods.

This finding has conformity with the results of some studies including Hesse (2007) and Bakradze and Billmeier (2007). In addition, the coefficient of real gross domestic product (Y) was obtained equivalent to -0.21 , which represents $\mathrm{Y}$ as the aggregate supply of economy; in this way, when the aggregate supply of economy increases, general level of prices will be decreased. The coefficient of nominal effective exchange rate according to theoretical expectations is negative and is equivalent to 0.19. This means that by depreciation of national money value, the price of export goods will be decreased for the foreigner and the price of import goods will be increased for home people and this can result in increasing the general level of prices inside the country. The coefficient of interest rate for three-month deposits was equal to 0.07 , which shows that when the desired interest rate increases, general level of prices will be increased in long-term. Of course, we should be careful that the level of this effect is very small compared with other variables. As a result, it can be said that the most important effective variable on inflation in long-term is the money supply and the variables of output and exchange rate will be followed by it in the next ranks.

All coefficients in the second vector have the expected sign and are compatible with the long-term equation nominal effective exchange rate. As it is expected, the coefficient of real gross domestic product $(\mathrm{Y})$ was equal to 1.44 , which represents a positive and strong effect of increasing the aggregate supply on improvement of national money value against other exchanges. In addition, in this long-term relationship, the coefficient of price level (DP) is equal to - 0.47 , which means a decrease in national money value as domestic prices in Iran's economy increases. At the end, the coefficient of foreign price index (WP) was estimated as equal to -1.92 , which shows that when foreign prices increase, the value of national money will be decreased. The VECM approach not only enables us to determine the direction of causality among the variables, but it also allows us to distinguish between the two types of Granger causality, namely short-run and long-run causality. The long-run causality from independent variables to the dependent variable is evaluated by testing the null hypothesis where the coefficient $(\lambda)$ of the error correction term $\left(\mathrm{EC}_{\mathrm{t}-1}\right)$ is zero. Table 2 shows two important points: First, the variables of $D E, D Y, D M$ and $D D P$ to be adjusted compared with the disequilibrium of the system and the coefficients of error correction of ecm (DP-DP $)$ or ecm (DE$\left.D E^{*}\right)$ in the equations are completely significant. Note that the joint significance test of these two feedback coefficients was used in the discussed equations. The significance of these coefficients means that the considered dependent variable is endogenous in VECM system and on the other hand, 
it indicates that there is a long-term causality relationship from the modeled variables on the dependent variable. Second point is that the variables of WP and R are not adjusted to any disequilibrium of system and the coefficients of error correction terms (ecm) are not meaningful in any of the above-mentioned equations. Therefore, these variables can be considered as weakly exogenous against the variables of price index and nominal effective exchange rate. As a result, in estimation of long-term relationships of $\mathrm{E}$ and DP, there is no need to model the variables of WP and $R$. Exogeneity of $R$ against other variables of model means that there is no policy- based rule like Taylor rule in respect of it.

Table 2

ECM estimation

\begin{tabular}{rccccccc}
\hline & DWP & DR & DE & DY & DM & DDP \\
\hline Ecm1 & 0.00 & 0.00 & 0.01 & -0.05 & -0.34 & -0.23 \\
& Ecm2 & & & $(0.07)$ & $(-0.47)$ & $(-3.96)$ & $(-5.82)$ \\
& & 0.00 & 0.00 & -0.16 & 0.11 & 0.03 & 0.02 \\
Note: 1- figures in parentheses are t statistics. 2-Over identification restrictions test along with imposing restriction on marginal variables LR test (rank=2);
\end{tabular}
Chi-Square(5)=2.4614(0.7823)

As it is observed in Table 3, the coefficient of error correction term shows that in each quarter, 23 percent of long-term disequilibrium of price index is corrected by the variable itself. Money supply against to disequilibrium of price level is adjusted in each season by a coefficient of 0.34 and decreases the available imbalance in price index which in some way, it represents the reaction of monetary authorities towards the available imbalances in price index as well as relative rigidity ${ }^{1}$ of prices in Iran's economy. On the other hand, the coefficient of error correction term, ecm (DP- $\left.D P^{*}\right)$ is not statistically significant in DE equation; therefore, nominal effective exchange rate is weakly exogenous compared to price index and doesn't play any role to decrease the imbalance of the first equation. According to the results obtained from the estimation of adjustment coefficients in Table 3 , the coefficient of error correction term, ecm $\left(E-E^{*}\right)$ was estimated as equal to -0.16 in DE equation, which is the biggest coefficient and represents that the correction foreign imbalance in Iran 's economy is mostly performed through exchange rate adjustment. On the other hand, although the variables of price index and GDP meaningfully react against foreign imbalance but the main load to achieve the balance in foreign sector is assumed by exchange rate. In addition, the coefficient of $\mathrm{E}$ error correction term in short-term equation of the aggregate supply was estimated about 0.11 , which is statistically significant and this means that with appreciation, the aggregate supply (Y) will increase. This finding is reasonable due to high dependency of output on the import of intermediary and capital goods. Price level is also adjusted following the temporal deviation of exchange rate from its equilibrium value with the coefficient of 0.02. But regarding to that the coefficient of error correction of exchange rate is not meaningful in LM1 equation, we conclude that nominal effective exchange rate is weakly exogenous and do not adjust against disequilibrium in money market. Therefore, it can be concluded that the identification of cointegrating vectors introduced by the estimated VAR system as long-term relationships between price level and nominal effective exchange rate is completely valid and reliable. The results of diagnostic tests are presented in Table 3 for the studied variables of VECM system.

Table 3

Diagnostic Tests

\begin{tabular}{lccc}
\hline White heteroscedastecity test on residual & \multicolumn{2}{c}{ LM test for serial correlation on residual } \\
\cline { 2 - 4 } Chi-square(33) $=717.4754(0.2522)$ & Lag & LM & $P-$ Value \\
\hline Normality test on residual & 1 & 36.0393 & 0.4668 \\
Jarque-Bera(12)=812.1808(0.0000) & 2 & 49.5570 & 0.0657 \\
& 3 & 41.1373 & 0.2557 \\
\hline
\end{tabular}


As it is observed, zero hypothesis of diagnostic tests including serial correlation $M$ test and white heteroscedasticity test are accepted in respect of the residual of VCEM model. Zero hypothesis in the above tests includes lack of serial correlation and heteroscedasticity in the residuals of VAR model. Of course, in this case, The Jarque-Bera test for normality suggests that normality is rejected at the usual probability levels for the residuals.

\subsection{Short-term Granger Causality tests}

Granger causality tests show short-term causal relationships between the variables of the system or the causality during the business cycles. In fact, these tests show whether the delays of a variable are introduced into the equation of another variable or not? Therefore, if $\left[Y_{t}\right]$ is not able to improve the prediction performance[ $\left.Z_{t}\right]$, [ $\left.Y_{t}\right]$ will not be Granger's Cause of $\left[Z_{t}\right.$ ] in this case. Short term Granger causality test of the explanatory variables is tested in VECM system through F or Wald statistic. Table 3 shows the results of short-term Granger causality tests causality as well as block exogenous Wald test based on the statistical significance test. The numbers in the table are P-value of Chai-Square. As it is observed, the fluctuations of foreign price level, interest rate and real GDP are not predicted by any of the other variables independently or in block. Therefore, these variables enjoy high exogenous degree in short-term. Furthermore, it is observed from the Table 3 that among the variables of the system, WP at the significance level of 0.001 and CPI at the significance level of 0.12 are the Granger causality for $E$ in business cycles.

\section{Table 4}

Short-term causative tests and block exogenous Wald test based on the estimated VECM

\begin{tabular}{lccccccc}
\hline & \multicolumn{5}{c}{ Dependent Variables } \\
\hline Causal Variables & $\Delta W P$ & $\Delta R$ & $\Delta E$ & $\Delta Y$ & $\Delta M$ & $\Delta D P$ \\
\hline$\Delta W P$ & --- & 0.5619 & 0.0012 & 0.3155 & 0.1314 & 0.2334 \\
$\Delta R$ & 0.2989 & --- & 0.4463 & 0.9269 & 0.3985 & 0.0692 \\
$\Delta E$ & 0.4664 & 0.8733 & --- & 0.8661 & 0.9131 & 0.1037 \\
$\Delta Y$ & 0.3515 & 0.4801 & 0.7856 & --- & 0.0205 & 0.0019 \\
$\Delta M$ & 0.2150 & 0.7605 & 0.1857 & 0.6291 & --- & 0.0013 \\
$\Delta D P$ & 0.3577 & 0.5439 & 0.1191 & 0.8258 & 0.3453 & -- \\
$\boldsymbol{A I I}$ & 0.4951 & 0.8483 & 0.0043 & $0 / 9188$ & 0.0572 & 0.0001 \\
\hline
\end{tabular}

- All numbers in table are p-value of chi-square statistics

Among these, WP has a high predictability power for $E$ while it seems that domestic price index enjoys weaker predictability for it. In addition, block exogenity Wald test of $E$ represents high endogenous being of this variable during business cycle. On the other hand, real GDP is also regarded as cyclical cause for money while WP is significance just at the level of 0.13 for Granger causality of money supply. Of course, block exogenous Wald test of money supply represents it is an endogenous variable. At the end, $\mathrm{R}$ at the significance level of $0.07, \mathrm{E}$ at the significance level of $0.1, \mathrm{LY}$ at the significance level of 0.002 and $\mathrm{M}$ at the significance level of 0.001 are Granger causality for domestic price (DP). Among these, just foreign price (WP) is not able to explain short-term fluctuations of domestic price.Also, block Wald test for DP represents very high endogenous of this variable during the cyclical periods. Therefore, it is obvious that in the studied system the DP during business periods is considered as the most endogenous variable and in addition to being affected by the aggregate supply of goods and services in short-term, it is completely influenced by potential policy tools of money supply, exchange rate and interest rate and these policy tools are not able to explain and predict the price in short-term. 


\section{Conclusion}

In this study, it was attempted to examine the existence of a stable and predictable relationship between the potential monetary policy tools and the target variables (the output and especially the inflation). The cointegration tests have confirmed the existence of two vectors or a long-term equilibrium relationship (compatible with the economic theory) among the studied variables. Our finding represented positive and strong effects of money supply on the price level in long-term and the negative effects of the aggregate supply on it. Negative coefficient of nominal effective exchange rate confirms that when domestic currency depreciate, domestic prices will be increased. Although the coefficient of short- term interest rate was positive and significant but it had a very slight effect. As a result, it can be declared that the main channel of monetary policy transmission mechanism in Iran' s economy, i.e. the interest channel, is inefficient. This finding is compatible with Bakradze and Billmeier (2007). In sum, the results represented that in long-term, money supply was the most important effective variable on the inflation followed by the variables of output and exchange rate, respectively. The second vector was considered as long- term equation of nominal effective exchange rate which all of its coefficients had the expected signs. The coefficient of real GDP represented the positive and strong effects of the aggregate supply on appreciation of national currency value. Money supply coefficient showed that when money supply increases, nominal effective exchange rate decreased (depreciation of national currency). Weak erogeneity tests (based on significance of ecm) showed that the variables of RS and LWCPI (interest rate and world price index) were weakly exogenous compare to the price index and nominal effective exchange rate. The exogenous test showed that the interest rate was completely exogenous compared to other model variables. This indicates that there is no policy-based rule like Taylor rule in Iran.

\section{References}

Al-Mashat, R., \& Billmeier, A. (2008). The monetary transmission mechanism in Egypt. Review of Middle East Economics and Finance, 4(3), 32-82.

Bakradze, G., \& Billmeier, A. (2007). Inflation targeting in Georgia: are we there yet?. IMF Working Papers, 1-33.

Bonato, L. (2007). Money and inflation in the Islamic Republic of Iran (Vol. 7). International Monetary Fund.

Boughrara, A., \& Erriadh, C. (2003). What do we know about monetary policy and transmission mechanism in Morocco and Tunisia. In 10th Annual Conference of Economic Research Forum (ERF), Marrakech, Morocco.

Cecchetti, S. G., \& Ehrmann, M. (1999). Does inflation targeting increase output volatility? An international comparison of policymakers' preferences and outcomes (No. w7426). National Bureau of Economic Research.

Coricelli, F., Égert, B., \& MacDonald, R. (2005). Monetary transmission mechanism in Central and Eastern Europe: Surveying the empirical evidence. In Finance and Consumption Conference, European University Institute, 14-15.

Dabla-Norris, E., \& Floerkemeier, H. (2006). Transmission mechanisms of monetary policy in Armenia: Evidence from VAR Analysis.

Dabla-Norris, E., Kim, D., Zermeno Livas, M. R., Billmeier, A., \& Kramarenko, V. (2007). Modalities of moving to inflation targeting in Armenia and Georgia. IMF Working Papers, 1-36.

Gottschalk, J., \& Moore, D. (2001). Implementing inflation targeting regimes: The case of Poland. Journal of Comparative Economics, 29(1), 24-39.

Hesse, H. (2007). Monetary policy, structural break and the monetary transmission mechanism in Thailand. Journal of Asian Economics, 18(4), 649-669.

Juks, R. (2004). Monetary Policy Transmission Mechanisms: A Theoretical and Empirical Overview. The Monetary Transmission Mechanism in the Baltic States. Eesti Pank, 39-60.

Mishkin, F. S., \& Schmidt-Hebbel, K. (2007). Does inflation targeting make a difference? (No. w12876). National Bureau of Economic Research. 